and mutant libraries. WIPO PCT Publication No. WO 0214490. 21 February, 2002.

8.Hahn, J., A. Luttinger, and D. Dubnau. 1996. Regulatory inputs for the synthesis of ComK, the competence transcription factor of Bacillus subtilis. Mol. Microbiol. 21: 763-775.

9.Canosi, U., G. Morelli, and T.A. Trautner. 1978. The relationship between molecular structure and transformation efficiency of some $S$. aureus plasmids isolated from B. subtilis. Mol. Gen. Genet. 166:259-267.

10.Miyazaki, K. and M. Takenouchi. 2002.
Creating random mutagenesis libraries using megaprimer PCR of whole plasmid. BioTechniques 33:1033-1038.

Received 5 June 2003; accepted 22 September 2003.

Address correspondence to Neelam $S$. Amin, Genencor International, 925 Page Mill Road, Palo Alto, CA 94304, USA. e-mail address: namin@genencor.com

\title{
Heparinase treatment of RNA before quantitative real-time RT-PCR
}

\author{
Mary Lynn Johnson, Chainarong Navanukraw, Anna T. Grazul-Bilska, \\ Lawrence P. Reynolds, and Dale A. Redmer \\ North Dakota State University, Fargo, ND, USA
}

BioTechniques 35:1140-1144 (December 2003)

Quantitative real-time reverse transcription PCR (RT-PCR) is a highly sensitive method for detecting changes in gene expression. Heparin was identified as an inhibitor of enzymatic reactions, similar to Moloney murine leukemia virus (MMLV) reverse transcriptase and Taq DNA polymerase reactions more than a decade ago (1-3). Most other inhibitors of RT-PCR may be removed from DNA or RNA during careful isolation of nucleic acids. Heparin presents a unique problem because it appears to co-purify with the RNA throughout numerous types of isolation procedures, even those using column purification (4). Methods for removing heparin from DNA and RNA using heparinase have been developed $(2,3,5,6)$. Although RNA is much more susceptible to degradation than DNA during these treatments, the use of an RNase inhibitor (RNasin ${ }^{\circledR}$; Promega, Madison, WI, USA) during the heparinase treatment appears to overcome the problems associated with using heparinase that is not certified RNase-free. Here we present a direct method for treating RNA samples with heparinase using the RNase inhibitor, buffer, and $\mathrm{MgCl}_{2}$ from the TaqMan ${ }^{\circledR}$ Reverse Transcription Reagents Kit
(Applied Biosystems, Foster City, CA, USA) and then proceeding with quantitative real-time RT-PCR without further quantification or purification of the treated RNA.

For this study, RNA was isolated separately from the granulosa and thecal layers of sheep ovarian follicles. Granulosa cells were removed from the follicles using cell culture medium containing heparin (100 U/mL Dulbecco's modified Eagle's medium) (DMEM) so that the follicular fluid would not clot during the procedure, whereas thecal cell layers were dissected from the follicle without the use of heparin. Isolation of RNA from granulosa and thecal layers using Tri Reagent ${ }^{\circledR}$ (Molecular Research Center, Cincinnati, OH, USA) was similar, except that polyacrylamide carrier was used for the granulosa cells. The quality and quantity of the RNA, measured on an Agilent 2100 Bioanalyzer (Agilent Technologies, Palo Alto, CA, USA), were excellent for both cell types (Figure 1).

Triplicate $20-\mu \mathrm{L}$ aliquots of RNA containing $30 \mathrm{ng}$ RNA each were reverse-transcribed for each sample using the random primers kit and protocol. The RT preparation was subjected to quantitative real-time RT-PCR using the ABI PRISM ${ }^{\circledR} 7000$ and the TaqMan Universal PCR Master Mix protocols (Applied Biosystems).

After discovering that the RNA from the thecal cells had vascular endothelial growth factor (VEGF) amplification and that RNA from granulosa cells had no VEGF amplification, the 18S rRNA amplification (TaqMan Pre-Developed Assay Reagents; Applied Biosystems), which is used as a positive control for eukaryotic gene expression and to normalize RNA concentrations, was performed on the granulosa samples to see if there was a problem with the RT reaction. The assay revealed that inhibition of the PCRs for the 18S rRNA assay was also present in granulosa cell RNA. An attempt to remove the unknown inhibitor(s) from the RNA using an RNA column purification clean-up procedure from Zymo Research (Orange, CA, USA) was unsuccessful.

Progressive dilutions of the RT of a thecal sample that amplified well during PCR with an RT from a sample of granulosa cell RNA that was PCRinhibited resulted in the progressive inhibition of amplification of the thecal sample (Figure 2). To identify heparin as the inhibitor present in the RNA, heparin and/or polyacrylamide carrier

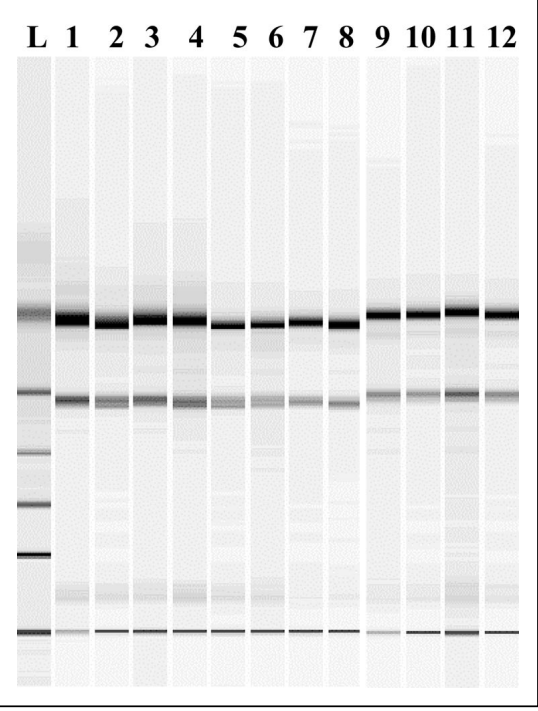

Figure 1. Computer-generated virtual gel image of total cellular RNA isolated from thecal and granulosa cells. Lanes 1-6 represent RNA from thecal cells, and lanes 7-12 represent RNA from granulosa cells. Lane $\mathrm{L}$ represents the RNA 6000 Ladder (Ambion, Austin, TX, USA) that is used as a quantification standard with the Agilent 2100 Bioanalyzer. 
were added to a thecal sample before RNA isolation, the RNA was isolated, and RT-PCR was performed. The polyacrylamide carrier alone did not appear to inhibit the RT of the RNA or subsequent PCR amplification, whereas heparin inhibited the reactions (data not shown).

We had a limited quantity of RNA from the heparin-contaminated granulosa cells, and the RNA had been quantified and diluted to the level needed for quantitative real-time RT-PCR. The heparinase methods used in other laboratories began with the treatment of a concentrated RNA sample and required posttreatment quantification and dilutions of the RNA $(2,3,5,6)$. Additionally, these methods required the use of $5 \mathrm{mM}$ Tris buffer at a $\mathrm{pH}$ of 7.5, with $1 \mathrm{mM} \mathrm{CaCl}_{2}$ in the reaction for the successful treatment of RNA with heparinase $(2,3,5,6)$. Thus, a modification of their heparinase techniques to one in which quantitative real-time RT-PCR could proceed directly was desirable.

The TaqMan Reverse Transcription Reagents Kit contains a $10 \times$ buffer with proprietary components and an approximate $\mathrm{pH}$ of 8.3. Heparinase has an isoelectric point (pI) of approximately 8.5, thus the $10 \times$ buffer appeared to be in a $\mathrm{pH}$ range compatible with the enzyme.

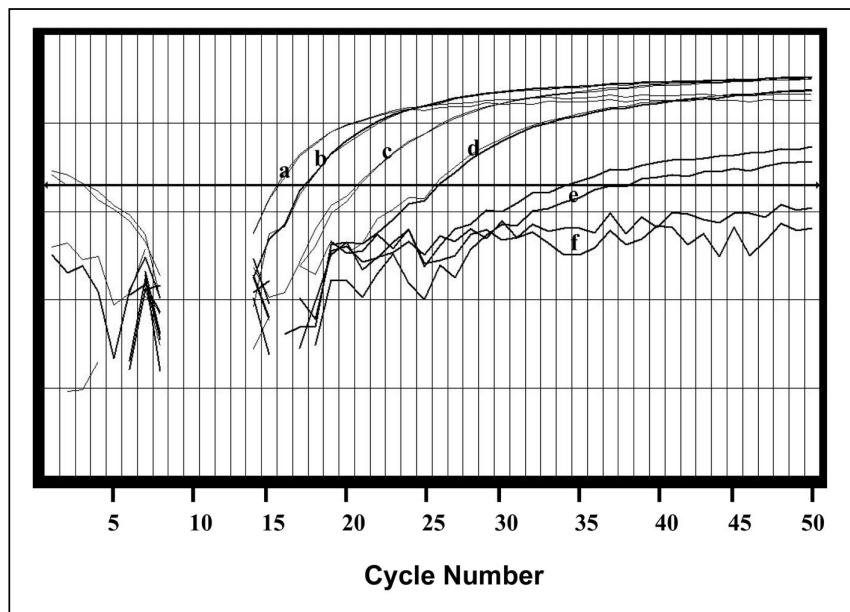

Figure 2. Progressive inhibition of the $18 S$ rRNA PCR amplification of a thecal sample when diluted with a heparin-inhibited sample from granulosa cells. The reverse transcription (RT) of (a) a thecal sample alone amplified well. (b-e) The progressive addition of inhibited granulosa cell RT preparation to the thecal RT. (b) Inhibited granulosa RT preparation $(0.5 \mu \mathrm{L})$ was combined with $2 \mu \mathrm{L}$ of the thecal RT preparation, which represents a 1: 5 dilution of the thecal RT with inhibited granulosa cell RT. (c) A 2:5 dilution of the thecal RT with inhibited granulose cell RT; (d), a 3:5 dilution; and (e), a 4:5 dilution. (f) The inhibited granulosa cell RT alone. This figure is a modification of the output from the real-time PCR instrument.
In addition, the kit supplied RNase inhibitor to prevent the degradation of the RNA during heparinase treatment.

Thus, $90 \mathrm{ng}$ of the RNA (representing a triplicate RT of approximately $20 \mu \mathrm{L}$ in size, each containing $30 \mathrm{ng}$ RNA) from 41 samples of granulosa were treated with heparinase I (Sigma, St. Louis, MO, USA) in the following sequence of reactions. First, $23.1 \mu \mathrm{L}$ RNA $(3.9 \mathrm{ng} / \mu \mathrm{L})$ were combined with $1.2 \mu \mathrm{L}$ RNase inhibitor (50 $\mathrm{U} / \mu \mathrm{L}), 3.0 \mu \mathrm{L} 10 \times \mathrm{RT}$ buffer, $2.7 \mu \mathrm{L}$ $\mathrm{gCl}_{2}(25 \mathrm{mM})$, and then with $0.9 \mu \mathrm{L}$ ing and pulse centrifuging briefly, the reactions were incubated at $25^{\circ} \mathrm{C}$ for $1 \mathrm{~h}$. Then, the rest of the components $\mathrm{MgCl}_{2}(25 \mathrm{mM}), 3.0 \mu \mathrm{L}$ random hexamers $(50 \mu \mathrm{M}), 12 \mu \mathrm{L}$ dNTP mixture $(10 \mathrm{mM})$, and $1.5 \mu \mathrm{L}$ MultiScribe ${ }^{\mathrm{TM}}$ Reverse Transcriptase $(50 \mathrm{U} / \mu \mathrm{L})$. The briefly, and divided into triplicate aliquots of $19-20 \mu \mathrm{L}$ that were incubated for $10 \mathrm{~min}$ at $25^{\circ}, 30 \mathrm{~min}$ at , and 5 min at $95^{\circ} \mathrm{C}$, as suggested by were diluted 1:5 with nuclease-free water and used as described above for quantitative real-time RT-PCR of the $18 \mathrm{~S}$ message.

Most of the RNA treated with heparinase (36 of 42 samples) was amplified in the 18S rRNA assay without signs of inhibition [cycle threshold $\left.\left(\mathrm{C}_{\mathrm{T}}\right)=14-16\right]$ (Figure 3 ). The incubation time with heparinase was increased to $2 \mathrm{~h}$ for the 6 samples that had $\mathrm{C}_{\mathrm{T}} \mathrm{s}$ greater than 20 . Four samples needed a 3-h treatment with twice as much heparinase to effectively remove the inhibition. The samples that did not respond to the first treatment with heparinase may have had an excessive amount of media containing heparin left on them during the freezing and storage at $-70^{\circ} \mathrm{C}$.

After treatment with heparinase, the granulosa and thecal samples were successfully assayed for 10 angiogenic genes. Gene expression for both granulosa and thecal samples were normalized to the expression of the $18 \mathrm{~S}$ rRNA to eliminate the possibility that residual heparin effects or differences in the amount of RNA used could influence the results.

For cases of severe heparin contamination, a kinetic experiment could be performed to optimize the heparinase treatment described above. Specific doses of heparin could be added to uncontaminated RNA samples, and the quantity of heparinase and the incubation time needed for successful quantitative real-time RT-PCR could be evaluated.

In summary, we present a useful technique for the removal of heparin from RNA immediately prior to quantitative real-time RT-PCR, using the

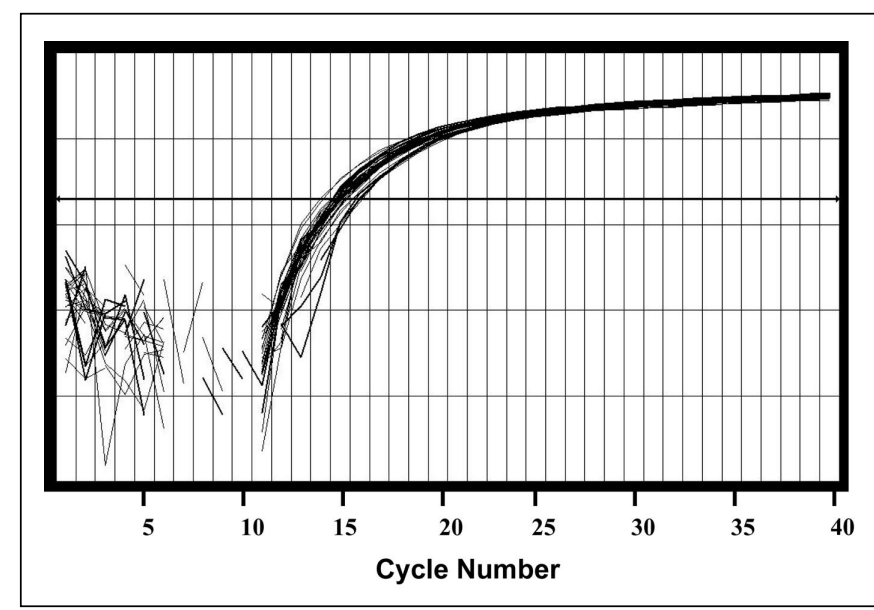

Figure 3. Recovery of the 18S rRNA PCR amplification of granulosa cell samples after treatment with heparinase. The $18 \mathrm{~S}$ rRNA PCR amplification was restored to normal [cycle threshold $\left(\mathrm{C}_{\mathrm{T}}\right)$ range of 13-16] after heparinase treatment. The granulosa cell samples were then successfully assayed for the expression of 10 angiogenic genes (data not shown). 
components of an RT kit to buffer the heparinase reaction. This is a quick and easy way to treat RNA samples potentially contaminated with heparin, such as RNA samples collected from lung or liver tissues or from unclotted samples of blood.

\section{ACKNOWLEDGMENTS}

We would like to thank Dr. Derek Killile and Dr. Robert Sparks, Department of Biochemistry, North Dakota State University, for suggesting that heparinase could be used to remove heparin from RNA, even though RNasefree heparinase might not be available. This led to a search through the literature and our development of the procedure described here.

\section{REFERENCES}

1.Holodniy, M., S. Kim, D. Katzenstein, M. Konrad, E. Groves, and T.C. Merigan. 1991. Inhibition of human immunodeficiency virus gene amplification by heparin. J. Clin. Microbiol. 29:676-679.

2.Izraeli, S., C. Pfleiderer, and T. Lion. 1991. Detection of gene expression by PCR amplification of RNA derived from frozen heparinized whole blood. Nucleic Acids Res. 19:6051.

3.Imai, H., O. Yamada, S. Morita, S. Suehiro, and T. Kurimura. 1992. Detection of HIV-1 RNA in heparinized plasma of HIV-1 seropositive individuals. J. Virol. Methods 36: 181-184.

4.Jung, R., C. Lubcke, C. Wagener, and M. Neumaier. 1997. Reversal of RT-PCR inhibition observed in heparinized clinical specimens. BioTechniques 23:24-28.

5.Beutler, E., T. Gelbart, and W. Kuhl. 1990. Interference of heparin with the polymerase chain reaction. BioTechniques 9:166.

6.Bai, X., S. Fischer, S. Keshavjee, and M. Liu. 2000. Heparin interference with reverse transcriptase polymerase chain reaction of RNA extracted from lungs after ischemia-reperfusion. Transpl. Int. 10:146-150.

Received 19 June 2003; accepted 26 September 2003.

Address correspondence to Mary Lynn Johnson, North Dakota State University, Department of Animal and Range Sciences, Fargo, ND, USA. e-mail: mary.lynn.johnson @ndsu.nodak.edu

\section{Unexpected sensitivity of synthetic Renilla luciferase control vectors to treatment with a cyclopentenone prostaglandin}

\author{
Xiaolan Zhang, Hui-Zi Chen, and Brad H. Rovin \\ The Ohio State University College of Medicine and Public Health, Columbus, \\ $\mathrm{OH}$, USA
}

BioTechniques 35:1144-1148 (December 2003)
Internal control reporter vectors are widely used in transient transfection assays to correct for inherent variations in transfection efficiency between experiments. The ideal control reporter vector should provide stable and high the expression should not be affected by experimental conditions, such as cotransfected vectors or the agonists used. However, internal control vectors do not necessarily provide an unbiased expression of the reporter gene, and

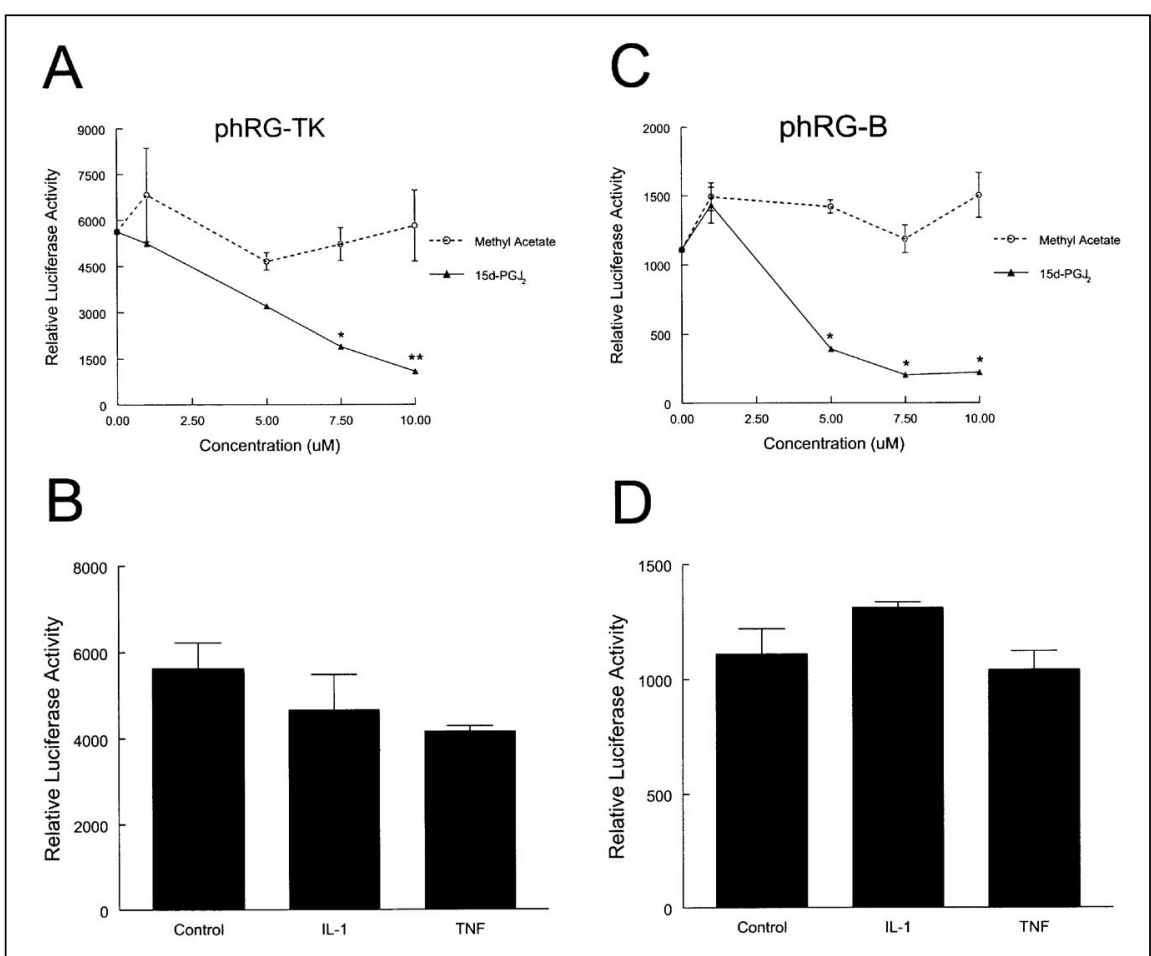

Figure 1. Luciferase activity of phRG-TK and phRG-B transfected into HEK 293 cells in response to treatment with $15 \mathrm{~d}-\mathrm{PG} \mathbf{J}_{2}$, interleukin $1 \beta$ (IL-1 $\beta$ ), or tumor necrosis factor- $\alpha(\mathrm{TNF}-\alpha)$. HEK 293 cells (ATCC, Manassas, VA, USA) were grown to 90\% confluence in Dulbecco's modified Eagle's medium (DMEM) plus 10\% fetal bovine serum (FBS) (Invitrogen, Carlsbad, CA, USA) and transfected

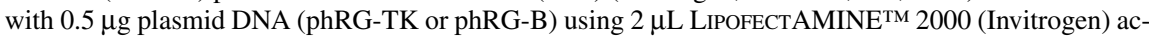
cording to the manufacturer's instructions. After $4 \mathrm{~h}$, the cells were washed and treated with the indicated concentrations of $15 \mathrm{~d}-\mathrm{PGJ}_{2}$ or a corresponding amount of methyl acetate (MA) carrier, media alone (control), IL-1 $\beta(1 \mathrm{ng} / \mathrm{mL})$, or TNF- $\alpha(10 \mathrm{ng} / \mathrm{mL})$ in serum-free medium for $20 \mathrm{~h}$. The cells were lysed, and the luciferase activity was measured using the Dual-Luciferase ${ }^{\circledR}$ Reporter Assay System (Promega). The luciferase activity was normalized to the protein concentration $(\mu \mathrm{g} / \mathrm{mL})$ of the lysate. Data are presented as the mean ( $\overline{\times} \pm$ SEM) of experiments done in triplicate and are representative of at least three independent experiments. Data were examined for significant differences using analysis of variance (ANOVA), followed by individual comparisons with the Bonferroni post-test. $P<0.05$ was considered significant. (A) Dose-dependent effect of $15 \mathrm{~d}_{-} \mathrm{PGJ}_{2}$ on phRG-TK activity. $* P<0.05$; $* * P<0.01$ versus MA. (B) Effect of IL-1 $\beta$ and TNF- $\alpha$ on phRG-TK activity. (C) Dose-dependent effect of $15 \mathrm{~d}-\mathrm{PGJ}_{2}$ on phRG-B activity. $* P<0.001$ versus MA. (D) Effect of IL-1 $\beta$ and TNF- $\alpha$ on phRG-B activity. 